\title{
Sustainable dyeing of wool fabric with Talaromyces purpurogenus
}

\author{
Himani Verma* \\ Department of Clothing and Textiles, College of Home Science, Govind .Ballabh Pant \\ University of Agriculture and Technology, Pantnagar, Udham Singh Nagar (Uttarakhand), \\ India \\ Anita Rani \\ Department of Clothing and Textiles, College of Home Science, Govind .Ballabh Pant \\ University of Agriculture and Technology, Pantnagar, Udham Singh Nagar (Uttarakhand), \\ India

\section{Manisha Gahlot} \\ Department of Clothing and Textiles, College of Home Science, Govind .Ballabh Pant \\ University of Agriculture and Technology, Pantnagar, Udham Singh Nagar (Uttarakhand), \\ India

\section{Alka Goel} \\ Department of Clothing and Textiles, College of Home Science, Govind .Ballabh Pant \\ University of Agriculture and Technology, Pantnagar, Udham Singh Nagar (Uttarakhand), \\ India

\section{Anil Kumar Sharma} \\ Department of Biological Sciences, College of Basic Sciences and Humanities, \\ Govind .Ballabh Pant University of Agriculture and Technology, Pantnagar, Udham Singh \\ Nagar (Uttarakhand), India \\ $\mathrm{CBSH}$ \\ ${ }^{*}$ Corresponding author. E-mail: verma.himani017@gmail.com \\ Abstract \\ Natural dyes had been used by human being since ancient times for colouring of various \\ materials including textiles. These were replaced completely by synthetic dyes, continu- \\ ous use of which created the problem of pollution and environmental degradation. With \\ the development of green technology and increased awareness of sustainability, the use \\ of non-allergic, non-toxic and eco-friendly natural dyes on textiles has become a matter of \\ significant importance. Among the natural sources of colourants, microorganisms such as \\ bacteria and fungi have gained interest in the field of textile coloration. In the present \\ study, the pigment solution yielded from growth of Talaromyces purpurogenus sp. on \\ organic waste was used for dyeing of wool fabric. Under the dyeing conditions i.e. 1:30 \\ $\mathrm{M}: \mathrm{L}$ ratio, $\mathrm{pH} 5,80^{\circ} \mathrm{C}$ temperature and 45 minutes dyeing time, the percent absorption \\ could reach $57 \%, 32 \%, 36 \%$ and $49 \%$ respectively. The wool fabric samples dyed with \\ the fungal dye exhibited very good to excellent washing and rubbing fastness properties. \\ The colour pigment obtained from fungal thus offered an opportunity to reduce impact on \\ plant resources for dye source exploration. So it can be concluded from the study that a \\ natural fungal dye could help to sustain the environment and to minimize the over \\ exploitation of natural resources.
}

Keywords: Natural dyeing, Percent absorption, Sustainability, Talaromyces purpurogenus, Wool fabric

\section{INTRODUCTION}

Natural dyes were the only source for colouring of textile materials from antiquity till nineteenth century. Natural dyes were originated from the sources of plant, animal, mineral, and microbial origins and these were used for textile colouration (Ali, 2007; Grover, 2011 and Bhandari, 2018). Use of natural dyes started to diminish after the fabrication of synthetic dyes in the second half of the nineteenth century. The prompt industrialization of textile production resulted in almost complete replacement of natural dyes by synthetic alternatives due to the fact that those were cheap,

\section{Article Info}

https://doi.org/

10.31018/jans.v11i4.2179

Received: October 21, 2019

Revised: November 22, 2019

Accepted: November 27, 2019

\section{How to Cite}

Verma, H. et al. (2019). Sustainable dyeing of wool fabric with Talaromyces purpurogenus. Journal of Applied and Natural Science, 11(4): 796 - 801 https://doi.org/10.31018/ jans.v11i4.2179 
spreading harmful diseases and intolerable effect on both human beings and environment (Ahlstrom, 2005; Devi, 2013; Wangatia, 2015).

Dyes are classified according to their methods of application or by their chemical structures. A group of atoms in dye molecules called chromophores such as azo, anthraquinone, methine, nitro, arylmethane, carbonyl and others, are responsible for the colour of dye. In addition, substituent called auxochromes, such as amine, carboxyl, sulphonate and hydroxyl, withdraw and/or donate electrons thereby generate or intensify the colour of the chromophores (Choudhury, 2010). Colouring of textiles adds aesthetic as well as economic value. It has also been desirable to colour textile for establishing its use for specific purpose. Colour in textiles had been used since ancient time to distinguish classes or position in hierarchy (Roy, 1977 and Gallop, 2005). Besides this colour in textiles intrigues consumers and producers alike to be used as tool for communicating the fashion (Valdez, 1994). In older days varied natural resources were used for developing colours to dye textiles (Khan, 2014; Indi and Chinta, 2008; Bhandari, 2018; Paliwal, 1991 and Ammayappan, 2009). This situation motivated man continuously to continue exploration of new resources for dye till 1856 when a chemist William Perkin happened to discover first synthetic dye. This discovery paved way to growth of synthetic dye industry that totally took over the natural dyes prevalent during older days. But continuous and extensive use of synthetic dyes resulted in environmental degradation to an extent that complete recovery is not possible. Such conditions prompted the concept of environment friendliness and generated awareness about need of sustainable development. The use of natural dyes had been revived as a step toward green production of textiles (Siva, 2007; Muthu, 2015).

Many natural dyes were used for colouration of wool fabrics. For example, terminalia arjuna fruits and madder (Kamel, 2011); Punica granatum (pomegranate) (Das, 2006); Rumex nepalensis and Girardinia diversifolia roots had been used to colour the wool fabric (Bhandari, 2018). Among natural resources, microbes had been identified as resource of future and explored extensively for diverse end uses. Development of colour from microbes had become possible through research and development programme taken up by private and government organisation as well as research institutions (Joshi, 2006; Mapari, 2010 and Parul, 2019).

Natural colorants from microorganisms have production advantages compared with similar products extracted from plants or animals, since they do not exhibit the problem of seasonal availability and are often more stable and soluble (Gunasekaran and Poorniammal 2008). The syn- thesis of colorants by plant species is slower than that by microorganisms and algae (Velmurugan et al. 2010). The colorants from fungi can be broadly classified chemically as carotenoids and polyketides. Fungal polyketide pigments range in structure from tetraketides to octaketides, which have four or eight $\mathrm{C}_{2}$ units that contribute to the polyketide chain. Representative classes include the anthraquinones, hydroxyanthraquinones, naphthoquinones, and azaphilone structures, each of which exhibit an array of color hues (Mapari et al. 2010).

Pigments from bacteria like Chromobacterium violaceum, Janthinobacterium lividum, Chromobacterium lividum and Pseudoalteromonas luteoviolacea have been used for dyeing textiles and good dyeing results have not only been obtained in connection with natural fibers such as silk, wool and cotton, but also with synthetic fibers such as nylon (Tan, 2005 ; Ryder, 2003). Variety of microbial pigments have been explored presently for textile colouration. For example, Monascus purpureus had been used to colour cotton fabric (Basant, 2016); Pseudomonas fluorescens had been used to colour cotton, silk and wool fabric (Mishra, 2018) and to colour cotton fabric (Bhargava, 2012). The microbial dye source when applied on textile substrate, it attributes functional characteristics like antimicrobial and antibacterial properties (Mishra, 2017; Basant, 2016 and Bhargava, 2012).

The aim of the present work was to optimize the dyeing parameters on wool fabric samples. The different dyeing parameters were used to optimize dyeing recipe for application of Talaromyces purpurogenus fungal dye.

\section{MATERIALS AND METHODS}

Textile material and its preparation for dyeing: The plain weave wool fabric was selected as a natural textile substrate to explore its compatibility to fungal dye source. Wool fabric was procured from Gandhi Ashram, Pantnagar, Uttarakhand. The construction details of the wool fabric are given in Table 1.

Wool fabric was prepared for dyeing by scouring process to remove possible impurities like dirt and any other finishing agent present on fabric.The fabric was washed with solution containing $0.5 \mathrm{~g} /$ liter non-ionic detergent solution at $40-45^{\circ} \mathrm{C}$ for 30 minutes, keeping the material to liquor ratio at 1:50. The scoured material was thoroughly washed with tap water and dried at room temperature.

Dye material: Coloured pigment producing strain of $T$. purpurogenus isolated from the waste food materials, wood etc., was procured from Department of Biological Sciences, College of Basic Sciences and Humanities, G.B.P.U.A. \& T., Pantnagar. Talaromyces purpurogenus was subcultured 
onto Czapek Yeast Extract Agar (CYA) plates containing $3 \%$ sucrose. After 7 days of cultivation at $30{ }^{\circ} \mathrm{C}$, the agar disks were cut from the plate. One disk was added to $50 \mathrm{ml}$ of sterile medium containing $3 \%$ sucrose, $0.3 \%$ nitrogen and $\mathrm{pH} 5$. After inoculation, the flask was placed on a rotary shaker at $150 \mathrm{rpm}, 30^{\circ} \mathrm{C}$ for 3 days. The production of shake flask culture was performed in 500 $\mathrm{ml}$ Erlenmeyer flask with $150 \mathrm{ml}$ cultivation medium. The cultivation parameters were $200 \mathrm{rpm}$, temperature $30^{\circ} \mathrm{C}$, pH 5 for 7 days. The $\mathrm{pH}$ of obtained dye pigment solution was $5 \mathrm{pH}$ (Parul, 2019).

Optimization of Dyeing Parameters: Four dyeing variables namely $M$ : $L$ ratio, dye $p H$, dyeing time and dyeing temperature were optimized in the present study. The optimization was done on the basis of percent absorption, rubbing and wash fastness rating of the dyed wool fabrics. Dyeing was performed in open water bath.

Optimization of $\mathbf{M}$ : $\mathbf{L}$ ratio: Five dye baths of $M$ : $L$ ratios 1:30. 1:50, 1:70, 1:90 and 1:110 respectively were prepared. Pre-soaked wool fabric samples were dyed in these solutions separately at $5 \mathrm{pH}$ for 60 minutes at $80^{\circ} \mathrm{C}$. Dyed samples were removed from the dye bath, cooled down, rinsed under tap water and dried in shade. The M: $\mathrm{L}$ ratio that yielded the dyed wool fabric with best percent absorption, rubbing fastness and wash fastness rating was taken as optimized MLR for dyeing wool with Talaromyces purpurogenus.

Optimization of dye $\mathrm{pH}$ : Five dye baths of $\mathrm{pH}$ $5,6,7,8$ and 9 respectively were prepared by taking optimized $\mathrm{M}$ : $\mathrm{L}$ ratio at $80^{\circ} \mathrm{C}$ for 60 minutes. Dyed samples were removed from the dye bath, cooled down and rinsed under tap water and dried in shade. The dye $\mathrm{pH}$ that yielded the dyed wool fabric with best percent absorption, rubbing fastness and wash fastness rating was taken as optimized $\mathrm{pH}$ for dyeing wool with Talaromyces purpurogenus.

Optimization of dyeing temperature: Five separate dye baths were prepared with optimized $\mathrm{pH}$ and optical density of all the solutions was recorded. Pre-soaked wool fabric samples were dyed in optimized M: $L$ ratio at $50,60,70,80$ and $90{ }^{\circ} \mathrm{C}$ respectively for 60 minutes. Dyed samples were removed from the dye bath, rinsed under tap water and dried in shade. The dyeing temperature that yielded the dyed wool fabric with best percent absorption, rubbing fastness and wash fastness rating was taken as optimized dyeing temperature for dyeing wool with Talaromyces purpurogenus.

Optimization of dyeing time: Pre-soaked wool fabric samples were dyed in separate solutions prepared using optimized $\mathrm{M}$ : $\mathrm{L}$ ratio and $\mathrm{pH}$ for 30 , $45,60,75,90$ minutes at optimized temperature. Dyed samples were removed from the dye bath, rinsed under tap water and dried in shade. The dyeing time that yielded the dyed wool fabric with best percent absorption, rubbing fastness and wash fastness rating was taken as optimized dyeing time for dyeing wool with Talaromyces purpurogenus.

Dyeing of wool fabric: The prepared wool fabric was dyed in open bath dyeing machine using $T$. purpurogenus fungal dye solution at the department of Clothing and Textiles College of Home Science, Pantnagar. Dyeing of wool fabrics was carried out using optimized dyeing conditions i.e. dye $\mathrm{pH}, \mathrm{MLR}$, dyeing temperature and dyeing time.

Analysis of colour characteristics: The dyed samples of wool were assessed for percent absorption and colour fastness properties as follows:

Percent absorption: The absorbance of the dye solution at $\lambda$ - max was recorded both before and after dyeing. To calculate the percentage absorption, the O.D. (optical density) was recorded and percent absorption was calculated by the following formula (Eq.1).

$\%$ Absorption= O.D of the dye liquor before dyeing - O.D of the dye liquor after dyeing / O.D of the dye liquor before dyeing $\times 100$ ............Eq.1

Assessment of colour fastness properties: The colour fastness properties were assessed against washing and rubbing for each dyed wool fabric sample. The change in color of dyed samples was assessed with Grey Scale No. 1 as per ISO: 105 methods. Table 2 enlists the fabric properties along with the standard test methods and equipment used for analysis.

The washing fastness was carried out as per recommendation of IS: 3361-1979 method using launder-o-meter (BIS, 1979).

The fastness to rubbing was carried out according to IS: $766-1988$ method (BIS, 1988) using crock meter. Table 3 shows the scale used for rating of dyed wool fabric fastness against rubbing and washing.

\section{RESULTS AND DISCUSSION}

The fungal origin pigment used in dyeing was in form of liquor with OD value 10 . It was used as such without further dilution. Hence this parameter (dye OD) was taken as constant. The prepared wool fabric was dyed with fungal origin pigment solution to optimize the dyeing recipe for its use in wool colouration.

Optimization for dyeing variables: The optimum conditions with respect to $\mathrm{pH}, \mathrm{M}$ : $\mathrm{L}$ ratio, dyeing temperature and dyeing time were determined separately for dyeing of wool fabric. The percent absorption and fastness properties were observed for selection of best fabric sample. Percent absorption was calculated on the basis of optical density of dye solution before and after dyeing.

Material to liquor ratio: The experiment was carried out to optimize the material to liquor ratio with $5 \mathrm{pH}$ of dye, $80^{\circ} \mathrm{C}$ dyeing temperature and 60 
minutes dyeing time. The wool fabric samples dyed with Talaromyces purpurogenus maintaining material to liquor ratio 1:30.1:50, 1:70, 1:90 and $1: 110$ respectively. The results of percent absorption and fastness rating are given in Table 4.

The absorption was found maximum at 1:30 material to liquor ratio and decreased with increase in

Table 1. Specifications of wool fabric used in the study.

\begin{tabular}{lll}
\hline S. N. & Specifications & Wool \\
\hline 1. & Fabric count per inch (warp/weft) & $44 \times 50$ \\
2. & Fabric thickness $(\mathrm{mm})$ & 0.095 \\
3. & Weight per unit area $\left(\mathrm{g} / \mathrm{m}^{2}\right)$ & 153 \\
\hline
\end{tabular}

material to liquor ratio. It might be due to binding of active sites on molecules of wool with dye molecule and further increase in volume of dye liquor did not help in absorption of dye molecules. Fastness ratings were also found best in the sample of 1: 30 MLR. Hence it was taken as optimum MLR for application of fungal dye on wool fabric.

Mishra (2007) dyed silk, wool and cotton yarns with Pseudomonas flurescens and also got high percent absorption in 1:30 material to liquor ratio.

Dye pH: Table 5 depicts the results of percent absorption of wool fabric samples dyed at five different $\mathrm{pH}$ of dye liquor viz., $\mathrm{pH}-5,6,7,8$ and 9 with optimized $\mathrm{M}$ : $\mathrm{L}$ ratio at $80^{\circ} \mathrm{C}$ for 60 minutes.

Table 2. Standard methods used for assessing dyed fabric sample properties.

\begin{tabular}{llll}
\hline S. N. & Fabric properties & Equipment used & Standard method \\
\hline 1 & Percent absorption & Spectrophotometer SSS100A & Commission International del Eclairage (CIE) \\
3 & Washing fastness & Launder-o-meter & BIS, 1979 \\
4 & Rubbing fastness & Crock meter & IS: 766-1988 \\
\hline
\end{tabular}

Table 3. Five point rating scale used for assessing change in colour and colour staining.

\begin{tabular}{llll}
\hline Gray scale Rating & Colour change (CC) & Colour staining (CS) & Wash fastness rating \\
\hline 5 & Negligible or no change & Negligible staining & Excellent \\
4 & Slight change & Slight staining & Very good \\
3 & Noticeable change & Noticeable staining & Good \\
2 & Considerable change & Considerable staining & Fair \\
1 & Much change & Heavy staining & Poor \\
\hline
\end{tabular}

Table 4. Percent absorption and fastness ratings of wool fabrics dyed with $T$. purpurogenus for different material to liquor ratio .

\begin{tabular}{|c|c|c|c|c|c|c|c|c|c|}
\hline \multirow[t]{3}{*}{ S. $\mathbf{N}$. } & \multirow[t]{3}{*}{ MLR } & \multirow{3}{*}{$\begin{array}{l}\text { Percent } \\
\text { absorption (\%) }\end{array}$} & \multirow{2}{*}{\multicolumn{3}{|c|}{ Washing fastness }} & \multicolumn{4}{|c|}{ Rubbing fastness } \\
\hline & & & & & & \multicolumn{2}{|c|}{ Wet } & \multicolumn{2}{|c|}{ Dry } \\
\hline & & & CC & ss & sc & Cc & sc & CC & sc \\
\hline 1 & $1: 30^{*}$ & 57 & 5 & 5 & 5 & 5 & 5 & $4-5$ & 5 \\
\hline 2 & $1: 50$ & 47 & 5 & 5 & 5 & $4-5$ & 5 & 4 & 5 \\
\hline 3 & $1: 70$ & 46 & $4-5$ & 5 & $4-5$ & 4 & 5 & $4-5$ & $4-5$ \\
\hline \multirow[t]{2}{*}{4} & $1: 90$ & 45 & 5 & 5 & $4-5$ & $4-5$ & $4-5$ & 5 & 5 \\
\hline & $1: 110$ & 44 & $4-5$ & 5 & $4-5$ & 4 & $4-5$ & 5 & 5 \\
\hline
\end{tabular}

*Optimum value

Table 5. Percent absorption and fastness ratings of wool fabrics dyed with $T$. purpurogenus at different $\mathrm{pH}$.

\begin{tabular}{llllllllll}
\hline S. N. & pH & \multirow{2}{*}{$\begin{array}{l}\text { Percent } \\
\text { absorption (\%) }\end{array}$} & \multicolumn{3}{c}{ Washing fastness } & \multicolumn{3}{c}{ Rubbing fastness } \\
\cline { 4 - 9 } & & & cc & ss & sc & cc & sc & cc & sc \\
\hline 1 & $5^{*}$ & 32 & 5 & 5 & 5 & $4-5$ & 5 & 5 & $4-5$ \\
2 & 6 & 28 & 5 & 5 & $4-5$ & $4-5$ & 5 & $4-5$ & $4-5$ \\
3 & 7 & 25 & $4-5$ & 5 & 5 & 4 & 5 & $4-5$ & 5 \\
4 & 8 & 24 & 5 & 5 & 5 & $4-5$ & $4-5$ & 5 & 5 \\
5 & 9 & 21 & $4-5$ & 5 & $4-5$ & 4 & $4-5$ & 5 & 5 \\
\hline
\end{tabular}

*Optimum value

Table 6. Percent absorption and fastness ratings of wool fabrics dyed with $T$. purpurogenus at different dyeing temperature.

\begin{tabular}{llllllllll}
\hline S. N. & Temperature & $\begin{array}{l}\text { Percent } \\
\text { absorption (\%) }\end{array}$ & \multicolumn{3}{c}{ Washing fastness } & \multicolumn{3}{c}{ Rubbing fastness } \\
\cline { 4 - 9 } & & & cc & ss & sc & cc & sc & cc & Sc \\
\hline 1 & 50 & 11 & $4-5$ & 5 & 5 & $4-5$ & 5 & $4-5$ & $4-5$ \\
2 & 60 & 24 & $4-5$ & $4-5$ & 5 & $4-5$ & 5 & 5 & $4-5$ \\
3 & 70 & 13 & 5 & 5 & 5 & 4 & 5 & 5 & 5 \\
4 & $80^{*}$ & 36 & 5 & 5 & 5 & $4-5$ & $4-5$ & 5 & 5 \\
5 & 90 & 31 & 5 & 5 & $4-5$ & 4 & $4-5$ & 5 & 5 \\
\hline
\end{tabular}

*Optimum value 
Verma, H. et al. / J. Appl. \& Nat. Sci. 11(4): 796 - 801 (2019)

Table 7. Percent absorption and washing fastness of wool fabrics dyed with $T$. purpurogenus for time through open dyeing method.

\begin{tabular}{|c|c|c|c|c|c|c|c|c|c|}
\hline \multirow[t]{3}{*}{ S. N. } & \multirow[t]{3}{*}{ Time } & \multirow[t]{3}{*}{ Percent absorption (\%) } & \multirow{2}{*}{\multicolumn{3}{|c|}{ Washing fastness }} & \multicolumn{4}{|c|}{ Rubbing fastness } \\
\hline & & & & & & \multicolumn{2}{|c|}{ Wet } & \multicolumn{2}{|c|}{ Dry } \\
\hline & & & CC & ss & sc & CC & sc & CC & sc \\
\hline 1 & 30 & 39 & 5 & $4-5$ & 5 & $4-5$ & 5 & $4-5$ & $4-5$ \\
\hline 2 & $45^{*}$ & 49 & 5 & 5 & 5 & $4-5$ & 5 & 5 & $4-5$ \\
\hline 3 & 60 & 43 & 5 & 5 & 5 & 4 & 5 & 5 & 5 \\
\hline 4 & 75 & 37 & 5 & 5 & 5 & $4-5$ & 5 & 5 & 5 \\
\hline 5 & 90 & 24 & 5 & 4 & $4-5$ & 4 & 5 & 5 & 5 \\
\hline
\end{tabular}

*Optimum value

Table 8. Optimum conditions for dyeing wool fabric using fungal origin dye $T$. purpurogenus.

\begin{tabular}{cll}
\hline S. N. & Dyeing parameters & Dyeing conditions \\
\hline 1. & Dye $\mathrm{pH}$ & 5 \\
2. & Dyeing temperature $\left({ }^{\circ} \mathrm{C}\right)$ & 80 \\
3. & Dyeing time (minutes) & 45 \\
4. & Dyeing material to liquor & $1: 30$ \\
\hline
\end{tabular}

Table 5 reveals that percent absorption and fastness ratings of wool fabric decreased as $\mathrm{pH}$ changes from 5 to 9 . The best result was obtained when wool fabric was dyed at $\mathrm{pH}$. The sample dyed with $\mathrm{pH}-5(32 \%)$ and minimum i.e. $21 \%$ was at $\mathrm{pH}$. At high $\mathrm{pH}$, the protein loses $\mathrm{H}+$ ions and at low $\mathrm{pH}$ the hydrogen ions are absorbed by carboxyl groups of protein present in the wool. Thus wool absorbs maximum dye at acidic medium (Mathur and Bhandari. 2001).

Dyeing temperature: Pre-soaked five fabric samples of wool were dyed with optimized $M$ : $L$ ratio and $\mathrm{pH}$ at $50,60,70,80$ and $90^{\circ} \mathrm{C}$ respectively for 60 minutes. The results of percent absorption and fastness ratings are given in Table 6 and shows that the percent absorption of wool fabric samples increased with increase in dyeing temperature from 50 to $80{ }^{\circ} \mathrm{C}$ and declined with further increase in dyeing temperature $90^{\circ} \mathrm{C}$. Maximum percent absorption i.e. $36 \%$ in the dyed wool fabric was observed at $80^{\circ} \mathrm{C}$. Bhargava(2012) dyed silk and cotton samples with Pseudomonas fluorescens dye and observed increase percent absorption of dyed samples with increase in dyeing temperature up to $80^{\circ} \mathrm{C}$. Silk and cotton samples showed highest percent absorption when dyed at this temperature.

In case of Pseudomonas aeruginosa dye also $80^{\circ} \mathrm{C}$ was selected as the optimum dyeing temperature for the dyeing of wool fabric as it exhibited better results. Selvi et al., (2011) had also stated that the pigment extract of Roseomonas fauriae were applied at $80^{\circ} \mathrm{C}$.

Dyeing time: Wool fabric samples were dyed for different time duration i.e. 30, 45, 60, 75, 90 minutes respectively to optimize dyeing time using optimized $\mathrm{M}$ : $\mathrm{L}$ ratio, $\mathrm{pH}$ and dyeing temperature. The details of percent absorption and fastness ratings of dyed fabric are given in Table 7 .

As evident from Table 7 that percent absorption of wool increased with increase in dyeing time from
30 to 45 minutes. Thereafter decrease in percent absorption was noticed with increase in dyeing time. Also fastness ratings for both washing and rubbing were very good to excellent at 45 minutes dyeing time. Hence 45 minutes was selected as optimum dyeing time. Thus it can be deducted from the Tables 4 to 7 that optimum variables for dyeing wool fabric with $T$. purpurogenus were 5 $\mathrm{pH}, 80^{\circ} \mathrm{C}$ and 45 minutes in open bath dyeing method.

Optimization of dyeing conditions using $T$. purpurogenus for wool fabric: It can be envisaged from Table 8 that the wool fabric could be dyed with fungal resource $T$. purpurogenus with excellent fastness by maintaining dye $\mathrm{pH} 5$ at temperature $80{ }^{\circ} \mathrm{C}$ for 45 minutes $1: 30 \mathrm{M}$ : $\mathrm{L}$ ratio in open dyeing machine.

\section{Conclusion}

It can be concluded from the study that the Talaromyces purpurogenus fungal solution could be used for dyeing of wool fabric. Optimization of dyeing conditions is essential to minimize the investment cost and to avoid inconsistency in the dyed fabric quality. The optimized dyeing conditions obtained were $M: L$ ratio $1: 30$, dyeing time 45 minutes, temperature $80^{\circ} \mathrm{C}$ and $\mathrm{pH} 5$. The wool fabric dyed with Talaromyces purpurogenus exhibited very good to excellent washing and rubbing fastness. Dyeing of wool fabric was done in open dyeing machine which are useful in small scale industry. This fungal dye can be effectively used in cottage industry without creating any type of effluent. Dyed wool fabric having high washing and rubbing fastness properties suggests to its use for handicraft items as well as dress materials.

\section{REFERENCES}

1. Ahlstrom, L., Eskilsson, C.S. \& Bjorklund, E. (2005) Determination of banned azo dyes in consumer goods. Trends Anal. Chem. 24 (1), 49-56. DOI: 10.1016/j.trac.2004.09.004.

2. Ali, S.; Nisar, N. and Hussain, T. (2007). Dyeing properties of natural dyes extracted from eucaliptus. Journal of the Textile Institute. 98(6):559-562.

3. Ammayappan, L. (2009). Applicaion of natural colours on woollen materials. In:Wool Technology, Karim, S. A., Shakyawar, D.B. and Joshi, A. (Eds.). Udaipur, India Agrotech Publishing Academy. Pp-336 
$-348$.

4. Basant, T. (2012). Natural Dye from Monascus purpureus: Optimization of Dyeing jProcess and Evaution of its colour Fastness and Functional Properties for Cotton and Silk Fabric. PhD Thesis. G.B Pant university of agriculture and technology.

5. Bhargava, D. (2012). Microbial dyes from Pseudomonas fluorescens and Pseudomonas aeruginosa: Extraction and optimization of dyeing process for textiles. PhD Thesis. G. B Pant university of agriculture and technology.

6. Bhandari, B. (2018). Optimization of dyeing conditions for wool and silk fabrics using dyes extracted from rumex nepalensis and girardinia diversifolia roots. PhD Thesis. G. B Pant university of agriculture and technology.

7. BIS. (1988). IS: 766-1988 (R2003) Method for determination of colour fastness of textile materials to washing: Test 3.

8. BIS. (1979). IS 3361:1979 (R2003) Method for determination of colour fastness of textile materials to washing: Test 2.

9. Das, D.; and Maulik, S. R. (2006). Dyeing of wool and silk with Punica Granatum. Indian Journal of Fiber and Textile Research. (31): 59-64.

10.Devi, M.; Ariharan, V.; Prasad and Annato, P. N. (2013). Eco-friendly and Potential source for Natural Dye. International Research Journal of Pharmacy, 4 (6):106-108.

11.Gallop, S. (2005). How to dye cloth. Retrieved on Jan. 24, 2007 from http://www.yale.edu/ynhti/ curriculum/units.

12.Grover, and Patni Vidya. (2011). Extraction and application of natural dye preparations from the floral parts of Woodfordia fruticosa (Linn.) Kurz. Indian Journal of Natural Products and Resources, 2.4: 403408.

13.Gunasekaran, S. and Poorniammal, R. (2008). Optimization of fermentation conditions for red pigment production from Penicillium sp. under submerged cultivation. African Journal of Biotechnol., 7:18941898. doi:10.1111/ jam.12110.

14.Hussain, A. S and Nawaz, R. (2009). Optimization of alkaline extraction of natural dye from Henna leaves and it's dyeing on cotton by exhaust method. Journal of Cleaner Production, (17): pp. 61.

15.Indi, Y. M. And Chinta, S. K. (2008). Application and properties of natural dye on cotton -Phyllanthus reticulates. Colourage, 54(8): 62-66.

16.Joshi, V.K. (2006). Production and applications of microbial colors in food: Present status and future strategy. In: Proceeding of national symposium on new horizons in Fermentation and Food Biotechnology. 14-29.

17.Kamel, M. M.; Abdelghaffar, F. and El-Zawahry, M. M. (2011). Ecofriendly dyeing of wool with a mixture of natural dyes," Journal of Natural Fibers, 8(4) pp. 289-307.

18.Khan, A.A.; Iqbal, N.; Adeel, S.; Azeem, M.; Batool, F. and Bhatti, I.A. (2014). Extraction of natural dye from red calico leaves: Gamma ray assisted improvements in colour strength and fastness properties. Dyes and Pigments. (103): 50-54.
19.Kulkarni, V.G. (2002). Dyeing of Indian Wool with Reactive Dye. Indian Journal of Fiber and Textile Research, (27):95-98.

20.Mapari, S.A.S.; Thrane, U. and Meyer, A.S. (2010). Fungal polyketide azaphilone pigments as future natural food colorants. Trends Biotechnol., 28: 300307.

21.Mathur, J.P. nad Bhandari, C. S. (2001). Use of beet sugar as wool colorant. Indian Journal of Fiber and Textile Research, 26(3): 313-316.

22.Mishra, A. (2007). Natural dyes from Pseudomonas fluorescens: Extration, characterization and optimization of dyeing process for textiles. Thesis: Ph. D. (Clothing \& Textiles), G.B.P.U.A. and T., Pantnagar.216p.

23. Mishra , A. ; Jahan, S. and Singh, U. S. (2017). BioColouration Of Textile Substrates With Microbial Dye. International Archive of Applied Sciences and Technology, 8 (4): 48-53.

24.Muthu, S. S. (2015). Functional aspects, eco-testing and environment impact of natural dyes in Handbook of Sustainable Apparel Production. Pp 337-340.

25.Paliwal, P. (1991). Extraction of natural dyes from Kilmora (Berberis aristata) and seul (Salmalia malabarica) and standardization of dyeing process for silk. Thesis, M.Sc. G.B. Pant University of Agri \& Tech, Pantnagr 87p.

26.Parul, (2019). Production and utilization of non-toxic biologically active fungal pigment. PhD Thesis .G.B. Pant University of Agriculture \& Tech, Pantnagar.

27.Choudhury, A. K. (2010). Textile Preparation and Dyeing. India The Society of Dyers and Colourists Education Charity.(1) :32-34.

28.Roy, M. (1977). Dyes in ancient and medieval India. Indian Journal of Historical Science, 13: 83-113.

29.Ryder, J. (2003). The use of microbes in the colouration and manufacture of textiles paper. Retrieved from http://www. textile art design fashion.pdf.

30.Selvi, K.; John, P.; J.A.; Ravindran, A. D and Vijaya, V. (2011). Quantitative Estimation of Insoluble Inorganic Phospahte Solubilization. International Journal of Science and Nature. 2(2): 292-295.

31.Siva , R. (2007). Status of natural dyes and dye yielding plants in India. Current Science, 92(7): 916925.

32.Tan, T. L.; Meyer, D. and Montforts, F. P. (2005). Violacein and Desoxyviolacein: Microbiological procedure for the biosynthesis of the natural blue-violet dyes. Retrieved from http://www.awibremerhaven.de/TT/viola/indexe. html.

33.Valdez, P and Mehrabia. (1994). Effect of color on emotions. Journal of experimental Psychology: General. 4(123): 394-409.

34.Velmurugan, P.; Lee, Y.H.; Venil, C.K. ; Lakshmanaperumalsamy, P. and Chae, J.C. (2010). Effect of light on growth, intracellular and extracellular pigment production by five pigment-producing filamentous fungi in synthetic medium. Journal of Bioscience and Bioengineering. 109:346-350.

35.Wangatia, L.M.; Tadesse, K. and Moyo, S. (2015). Mango Bark Mordant for Dyeing Cotton with Natural Dye: fully eco-friendly natural dyeing. International Journal of Textile Science 4(2): 36-40 